\title{
Recombination Parameters in InGaAsSb Epitaxial Layers for Thermophotovoltaic Applications
}

\author{
R.J. Kumar, J.J. Gutmann, J.M. Borrego, P.S. Dutta, \\ C.A. Wang, R.U. Martinelli, G. Nichols
}

\begin{abstract}
This report was prepared as an account of work sponsored by the United States Government. Neither the United States, nor the United States Department of Energy, nor any of their employees, nor any of their contractors, subcontractors, or their employees, makes any warranty, express or implied, or assumes any legal liability or responsibility for the accuracy, completeness or usefulness of any information, apparatus, product or process disclosed, or represents that its use would not infringe privately owned rights.
\end{abstract}




\title{
Recombination Parameters in InGaAsSb Epitaxial Layers for Thermophotovoltaic Applications
}

\author{
R. J. Kumar ${ }^{a}$, R. J. Gutmann, J. M. Borrego, , P. S. Dutta ${ }^{a}$, C. A. Wang ${ }^{b}$, R. U. Martinelli ${ }^{c}$ \\ and G. Nichols ${ }^{d}$ \\ ${ }^{a}$ Center for Integrated Electronics, Rensselaer Polytechnic Institute, Troy, NY 12180 \\ ${ }^{b}$ Lincoln Laboratory, Lexington, MA 02420 \\ ${ }^{\mathrm{c}}$ Sarnoff Corporation, Princeton, NJ 08543 \\ dockheed Martin, Schenectady, NY 12301
}

\section{ABSTRACT}

Radio-frequency (RF) photoreflectance measurements and one-dimensional device simulations have been used to evaluate bulk recombination parameters and surface recombination velocity (SRV) in doubly-capped $0.55 \mathrm{eV}, 2 \times 10^{17} \mathrm{~cm}^{-3}$ doped $\mathrm{p}$-InGaAsSb epitaxial layers for thermophotovoltaic (TPV) applications. Bulk lifetimes of 90-100 ns and SRVs of $680 \mathrm{~cm} / \mathrm{s}$ to $3200 \mathrm{~cm} / \mathrm{s}$ (depending on the capping layer) are obtained, with higher doping and higher bandgap capping layers most effective in reducing SRV. RF photoreflectance measurements and one-dimensional device simulations are compatible with a radiative recombination coefficient (B) of $3 \times 10^{-11} \mathrm{~cm}^{3} / \mathrm{s}$ and Auger coefficient (C) of $1 \times 10^{-28} \mathrm{~cm}^{6} / \mathrm{s}$.

\section{INTRODUCTION}

Since thermophotovoltaic (TPV) devices generate electricity directly from a relatively low temperature heat source, low bandgap $\left(\mathrm{E}_{\mathrm{g}}<0.75 \mathrm{eV}\right)$ semiconductors are required to simultaneously maximize both efficiency and power density [1]. A source of heat is coupled with a radiator to emit infrared radiation. An array of interconnected semiconductor diodes converts above-bandgap photons to electricity. To improve efficiency, the TPV system rechannels belowbandgap photons back to the radiator using a spectral control filter [2].

The bandgap of the TPV diode is placed near the peak of the incident greybody spectrum from the radiator to simultaneously maximize both efficiency and power density. While higher power density can be achieved by lowering the bandgap and capturing a larger fraction of the spectrum, the diode dark current increases which adversely affects both the open circuit voltage and fill factor. For a radiator temperature of $\sim 1000{ }^{\circ} \mathrm{C}$, the best compromise between power density and efficiency is obtained by using a bandgap in the range of 0.50 to $0.60 \mathrm{eV}$. High quality InGaAsSb TPV devices have been fabricated on $\mathrm{GaSb}$ substrates $[3,4]$.

Figure 1(a) shows the layers of a typical GaInAsSb TPV cell grown by organometallic vapor phase epitaxy (OMVPE), with the GaInAsSb alloy composition corresponding to the desired bandgap $(\approx 0.55 \mathrm{eV})$. The structure uses a thick p-type emitter layer compared to the $\mathrm{n}$ type base layer because of the large minority carrier diffusion length in the p-type quaternary alloy compared to the n-type alloy and difficulty in making ohmic contacts to thin n-type layers. The $\mathrm{AlGaAsSb}$ or $\mathrm{GaSb}$ window layer is used to reduce surface recombination which is detrimental to device performance. The best performing InGaAsSb TPV devices have been achieved with this device structure, as discussed elsewhere [5]. 


\begin{tabular}{|ll|}
\hline p-GaSb & Contact \\
\hline p-AlGaAsSb or GaSb & Window \\
\hline p-InGaAsSb & Emitter \\
\hline n-InGaAsSb & Base \\
\hline n-GaSb & Substrate \\
\hline
\end{tabular}

(a)

\begin{tabular}{|ll|}
\hline GaSb/AlGaAsSb & Window \\
\hline p-InGaAsSb & Active Layer \\
\hline GaSb/AlGaAsSb & Window \\
\hline n-GaSb & Substrate \\
\hline
\end{tabular}

(b)

Figure 1. (a) Epitaxial InGaAsSb/AlGaAsSb/GaSb TPV device structure [5]

(b) OMVPE grown p-InGaAsSb lifetime structure

\section{MINORITY CARRIER LIFETIME}

In the TPV device depicted in Figure 1(a), the carriers generated by the above-bandgap radiation must be able to diffuse through the p-type emitter to the depletion region. Maximizing the diffusion length, given by $L=(D \tau)^{1 / 2}$ (where $D$ is the diffusion coefficient and $\tau$ is the minority carrier lifetime), and decreasing SRV at interfaces (window-emitter interface) are important in optimizing device performance. The saturation current ( $\left.\mathrm{I}_{\mathbf{S}}\right)$ is also minimized by maximizing the recombination lifetimes in the emitter and base regions, which increases the open circuit voltage. Therefore, the minority carrier lifetime and SRV are important parameters for quantum efficiency and open circuit voltage in a TPV device; knowledge of these recombination processes is important for optimizing the cell operation.

Lifetime test structures (Figure 1(b)) grown at Lincoln Laboratory using OMVPE have been used to determine the recombination parameters in $0.55 \mathrm{eV}$ p-InGaAsSb material. The capping (window) layers at the front and back are used to minimize surface recombination and the active layer thickness is varied to allow determination of the SRV. For a thin doubly-capped structure, the effective decay time of carriers is the sum of contribution from bulk and surface recombination, as given by the equation,

$$
\frac{1}{\tau_{\text {eff }}}=\frac{1}{\tau_{B}}+\frac{S_{1}+S_{2}}{W}
$$

where $\tau_{\text {eff }}$ is the effective decay time of the carriers, $\tau_{B}$ is the bulk lifetime, $S_{1}$ and $S_{2}$ are the front and back SRVs and $W$ is the thickness of the sample. Assuming low level injection conditions and $S_{1}=S_{2}=S$, bulk lifetime can be expressed in terms of individual mechanisms as follows,

$$
\frac{1}{\tau_{\text {eff }}}=\frac{1}{\tau_{\text {Aug }}}+\frac{1}{\tau_{\text {Rad }}}+\frac{1}{\tau_{S R H}}+\frac{2 S}{W}=C N^{2}+B N+\frac{1}{\tau_{S R H}}+\frac{2 S}{W}
$$

In the above equation, $\tau_{\mathrm{Aug}}, \tau_{\mathrm{Rad}}, \tau_{\mathrm{SRH}}$ are the Auger, Radiative and Shockley-Read-Hall lifetimes, $\mathrm{C}$ is the Auger coefficient, $\mathrm{B}$ is the radiative recombination coefficient and $\mathrm{N}$ is the doping concentration. Recent work has shown that radiative and Auger recombination (and not Shockley-Read-Hall (SRH) recombination) are the dominant bulk recombination mechanisms in these materials $[6,9]$. 
Theoretical calculations and experiments give radiative recombination coefficients (B) between $10^{-10}$ to $10^{-11} \mathrm{~cm}^{3} / \mathrm{s}$ and Auger coefficients (C) between $10^{-26}$ to $10^{-29} \mathrm{~cm}^{6} / \mathrm{s}$, for low bandgap antimonide materials as summarized by Charache et al. [6]. Theoretical calculations of recombination rates in long wavelength detectors by Flatte et al. estimate Auger coefficients in the range $1-2 \times 10^{-27} \mathrm{~cm}^{6} / \mathrm{s}[7,8]$ and have been used in predicting TPV device performance capabilities [4].

The aim of the present work is to obtain estimates for the radiative and Auger recombination parameters as well as SRV using GaSb and AlGaAsSb capping layers. The samples with different active layer thicknesses are used to estimate the SRVs for different capping layers and one-dimensional simulations using PC-1D® are used to estimate the bulk recombination parameters.

\section{EXPERIMENTAL TECHNIQUE}

A radio-frequency (RF) photoreflectance technique, which senses changes in sample conductivity as carriers recombine following excitation by a laser pulse, is used for the measurements [9]. Earlier work by Ahrenkiel et al. [10] and Saroop et al. [9] successfully applied this technique to characterize antimonide-based substrates and epitaxial layers using double heterostructure confinement. A Laser Photonics YQL-102 Q-switched Nd:YAG laser operating at $1.06 \mu \mathrm{m}$ with a nominal pulse width and decay time of $13.5 \mathrm{~ns}$ and $5 \mathrm{~ns}$ respectively is used to excite carriers in the semiconductor active layer. The generated carriers cause an increase in the conductivity and the output signal amplitude is directly proportional to the change in sample conductivity. Measurements are typically done at a laser pulse energy of $1.5 \mathrm{~mJ} / \mathrm{pulse}$, with measurements at $15 \%$ and $5 \%$ of the full intensity achieved by placing optical filters in the path of the laser beam to investigate the effect of injection level.

\section{ONE-DIMENSIONAL DEVICE SIMULATIONS}

PC-1Dß is a computer program which solves the fully coupled nonlinear equations for the quasi-one-dimensional transport of electrons and holes in crystalline semiconductor devices [11]. For the RF photoreflectance simulations, the sample material and structural parameters are specified, including recombination parameters such as Auger and radiative recombination coefficients and front and back SRVs. The sample is excited with a pulse of appropriate wavelength and intensity, and the excess sheet conductance of the sample versus time is obtained. The integrated conductivity from the front to the back surface relative to the value at equilibrium is calculated; this value is assumed proportional to the RF photoresponse. The effect of the different parameters on the long decay time can be observed by varying the individual recombination parameters and repeating the simulations.

Figure 2 shows the dependence of the photoconductivity transient on Auger coefficient for a $5 \mu \mathrm{m}$ thick $0.55 \mathrm{eV}$ quaternary material doped at $2 \times 10^{17} \mathrm{~cm}^{-3}$ for three Auger coefficients differing from each other by a half order of magnitude. The nominal values used for the other recombination parameters are: $\tau_{\mathrm{SRH}}=1000 \mathrm{~ns}, \mathrm{~B}=6 \times 10^{-11} \mathrm{~cm}^{3} / \mathrm{s}$, front and back SRVs $=10^{3}$ $\mathrm{cm} / \mathrm{s}$. The transient decay times from the simulations agree quite well with the calculated effective decay times from equation (2). When the long decay times are known from the RF photoreflectance measurements, the recombination parameters can be estimated by varying them until the transient decay times from the simulations matches the measured decay time. 


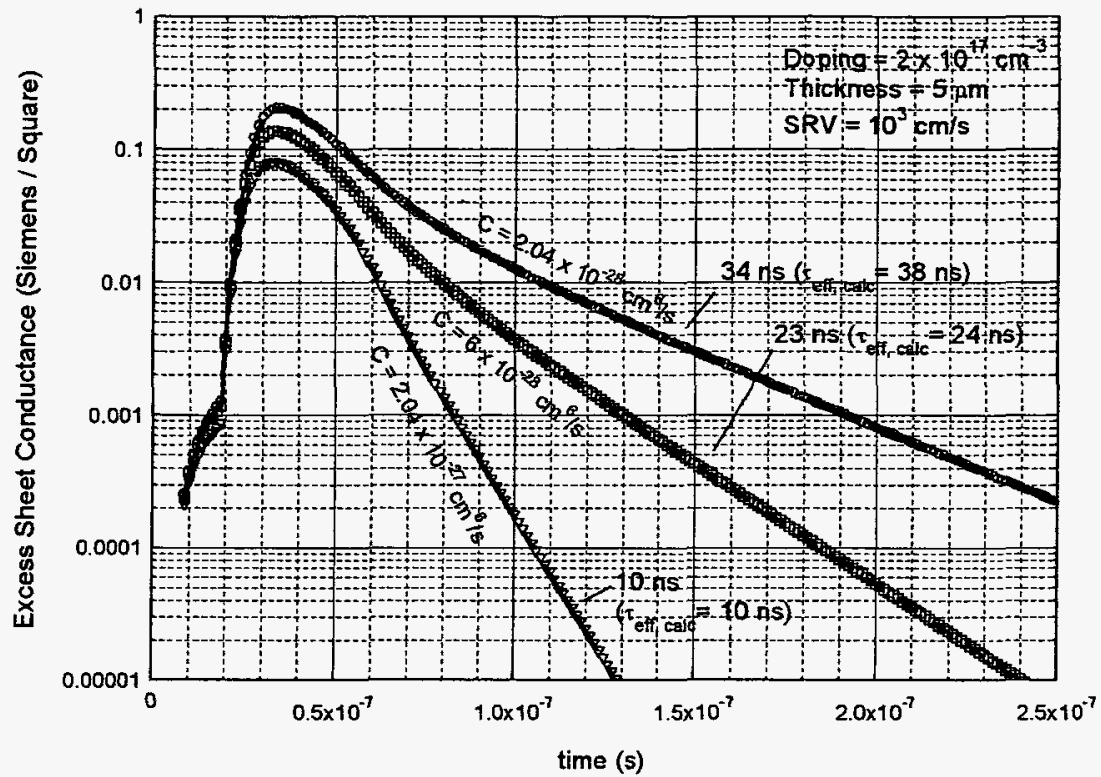

Figure 2. Simulation of dependence of photoconductivity transient on Auger coefficient for $0.55 \mathrm{eV}$ InGaAsSb (1064 nm, $15 \%$ intensity).

\section{RESULTS AND DISCUSSION}

RF photoreflectance measurements were performed on three series of InGaAsSb lifetime structure samples grown at Lincoln Laboratory. All series have $2 \times 10^{17} \mathrm{~cm}^{-3}$ p-doped active layers with sample thicknesses varying from $1.2 \mu \mathrm{m}$ to $5 \mu \mathrm{m}$. The 01-484 to $01-488$ series has undoped $\left(2 \times 10^{17} \mathrm{~cm}^{-3}\right)$ AlGaAsSb capping layers, 01-506 to 01-510 series has highly doped (2 $\left.\times 10^{18} \mathrm{~cm}^{-3}\right) \mathrm{p}$-GaSb capping layers, while the $01-489$ to $01-492$ series has undoped $\left(1 \times 10^{16}\right.$ $\mathrm{cm}^{-3}$ ) GaSb capping layers.

The photoresponse obtained from the 01-484 to 01-488 series at $1064 \mathrm{~nm}$ and 1.5 $\mathrm{mJ} /$ pulse is shown in Figure 3; the observed long decay times for the samples vary from $43 \mathrm{~ns}$ to $80 \mathrm{~ns}$ as shown in the figure. A plot of the inverse of the effective decay times vs. the inverse of active layer thicknesses can be used to extract the bulk lifetime and SRV: bulk lifetime

$=1 / y$-intercept and SRV $=$ slope/2. Using this procedure for the 01-484 to 01-488 series results in a bulk lifetime $=81 \mathrm{~ns}$ and SRV $=680 \mathrm{~cm} / \mathrm{s}$. Using PC-1D to simulate the decay times of this series with an $\mathrm{SRV}=680 \mathrm{~cm} / \mathrm{s}$ and a nominal SRH lifetime of $1 \mu \mathrm{s}$, the following radiative and Auger coefficients are obtained to match the measured decay times: $\mathrm{B}=3 \times 10^{-11} \mathrm{~cm}^{3} / \mathrm{s}, \mathrm{C}=1 \mathrm{x}$ $10^{-28} \mathrm{~cm}^{6} / \mathrm{s}$.

RF photoreflectance measurements at $1064 \mathrm{~nm}$ and $1.5 \mathrm{~mJ} /$ pulse were also done on the 01-506 to 01-510 series, with the long decay times varying from $27 \mathrm{~ns}$ for the $1.2 \mu \mathrm{m}$ thick sample to $54 \mathrm{~ns}$ for the $4 \mu \mathrm{m}$ sample. Extracting the bulk lifetime and SRV using the same procedure as above results in, bulk lifetime $=100 \mathrm{~ns}$ and SRV $=1350 \mathrm{~cm} / \mathrm{s}$. Using PC-1D to simulate the decay times gives the following parameters for this series: $\mathrm{B}=2.5 \times 10^{-11} \mathrm{~cm}^{3} / \mathrm{s}, \mathrm{C}=$ $1 \times 10^{-28} \mathrm{~cm}^{6} / \mathrm{s}$ (for SRV $=1350 \mathrm{~cm} / \mathrm{s}$ and a nominal SRH lifetime of $1 \mu \mathrm{s}$ ).

The 01-489 to 01-492 series consists of four samples with $2 \times 10^{17} \mathrm{~cm}^{-3}$ doped pInGaAsSb active layers and nominally undoped $\left(\sim 10^{16} \mathrm{~cm}^{-3}\right) \mathrm{GaSb}$ capping layers; the four samples vary in thickness from $1.2 \mu \mathrm{m}$ to $4 \mu \mathrm{m}$. For this series, only the $4 \mu \mathrm{m}$ thick sample (01489) has a measurable long decay time (37 ns). The thinner samples (1.2 $\mu \mathrm{m}, 1.5 \mu \mathrm{m}$ and $2.1 \mu \mathrm{m})$ 


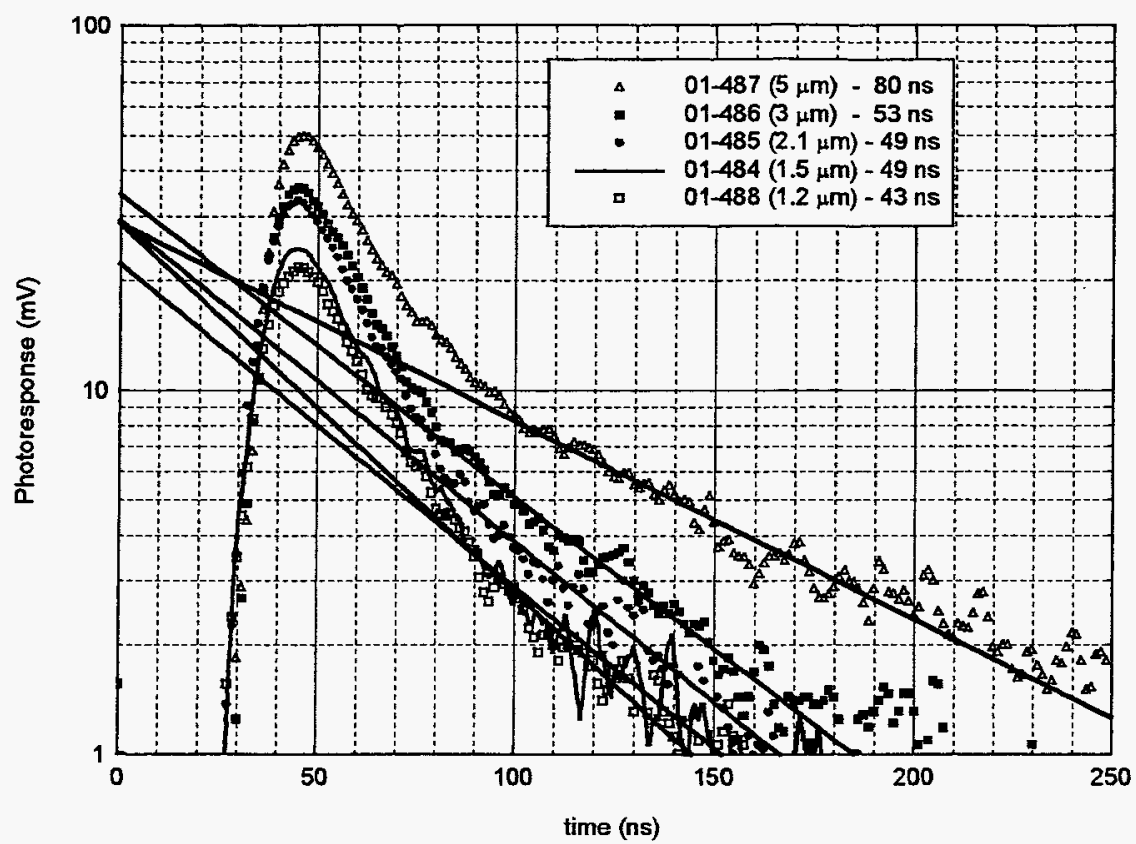

Figure 3. Photoresponse from OMVPE samples 01-484 to 01-488 (1064 nm, $1.5 \mathrm{~mJ} /$ pulse)

have long decay times too low to be measured. The active layer doping concentration of this series $\left(2 \times 10^{17} \mathrm{~cm}^{-3}\right)$ is the same as that of series 01-506 to 01-510 and 01-484 to 01-488, which showed bulk lifetimes of $100 \mathrm{~ns}$ and $81 \mathrm{~ns}$ respectively. Using the average $(90 \mathrm{~ns})$ for the bulk lifetime of the $4 \mu \mathrm{m}$ thick sample, an SRV of $\sim 3200 \mathrm{~cm} / \mathrm{s}$ is required to obtain an effective long decay time of $37 \mathrm{~ns}$. With these values, the calculated long decay times for the thinner samples are near the resolution limit of the photoreflectance equipment. Therefore, these estimates of the bulk lifetime and SRV for this series are less precise since a plot of $1 / \tau(\mathrm{eff})$ vs. $1 / \mathrm{W}$ cannot be used.

The SRVs and bulk lifetimes of the three series of samples are summarized in Table 1. The AlGaAsSb capping layer results in the lowest SRV and the undoped GaSb capping layer give the largest SRV. The results indicate that the capping layer is most effective in reducing SRV when the doping is high relative to the active layer and also for a higher bandgap. An independent measurement of the lifetime of these three series using a photoluminescence technique showed comparable values for bulk lifetimes and SRVs [5].

\begin{tabular}{|c|c|c|c|c|}
\hline Series & $\begin{array}{c}\text { Capping } \\
\text { Layer }\end{array}$ & $\begin{array}{c}\text { Active } \\
\text { Layer }\end{array}$ & $\begin{array}{c}\text { Bulk } \\
\text { Lifetime }\end{array}$ & $\begin{array}{c}\text { SRV } \\
(\mathrm{cm} / \mathrm{s})\end{array}$ \\
\hline $01-484$ to $01-488$ & $2 \times 10^{17} \mathrm{AlGaAsSb}$ & $2 \times 10^{17} \mathrm{InGaAsSb}$ & $81 \mathrm{~ns}$ & 680 \\
\hline $01-506$ to $01-510$ & $2 \times 10^{18} \mathrm{GaSb}$ & $2 \times 10^{17} \mathrm{InGaAsSb}$ & $100 \mathrm{~ns}$ & 1350 \\
\hline $01-489$ to $01-492$ & $1 \times 10^{16} \mathrm{GaSb}$ & $2 \times 10^{17} \mathrm{InGaAsSb}$ & $90 \mathrm{~ns}$ & $3200^{*}$ \\
\hline
\end{tabular}

Table 1. Comparison of bulk lifetimes and SRVs of $2 \times 10^{17} \mathrm{~cm}^{-3}$ doped OMVPE samples (* values for 01-489 to 01-492 less precise as described in text) 


\section{SUMMARY AND CONCLUSIONS}

$\mathrm{RF}$ photoreflectance measurements and one-dimensional device simulations were used to estimate recombination parameters in $0.55 \mathrm{eV}, 2 \times 10^{17} \mathrm{~cm}^{-3}$ doped, epitaxially grown pInGaAsSb lifetime structures. Measurements give a bulk lifetime of 90 to $100 \mathrm{~ns}$ and SRV of 680 to $3200 \mathrm{~cm} / \mathrm{s}$. The lowest SRV is observed for AlGaAsSb capping layers while the highest $\mathrm{SRV}$ is observed for undoped $\mathrm{GaSb}$ capping layers. Simulations matching the photoconductivity transients to the observed long decay times give Auger coefficient $\mathrm{C} \sim 1 \times 10^{-28} \mathrm{~cm}^{6} / \mathrm{s}$ and radiative coefficient (B) $\sim 3 \times 10^{-11} \mathrm{~cm}^{3} / \mathrm{s}$ for the quaternary materials.

\section{REFERENCES}

1. T. Coutts and M. Fitzgerald, "Thermophotovoltaics", Scientific American, pp. 90-95 (September 1998).

2. G. Charache, D. DePoy and P. Baldasaro, "Design Issues in Thermophotovoltaic Systems", Compound Semiconductor, Fall 1, pp. 36-40 (1998).

3. C. W. Hitchcock, R. J. Gutmann, J. M. Borrego, I. B. Bhat and G. W. Charache, "Antimonide-Based Devices for Thermophotovoltaic Applications", IEEE Transactions on Electron Devices, Volume 46, Number 10, pp. 2154-2161 (October 1999).

4. J. M. Borrego, C. A. Wang, P. S. Dutta, G. Rajagopalan, R. J. Gutmann, I. B. Bhat, H. Ehsani, J. Beausang, G. Nichols, and P. F. Baldasaro, "Performance Limits of Low Bandgap Thermophotovoltaic Antimonide-Based cells for Low Temperature Radiators", Proceedings of Thermophotovoltaic Generation of Electricity: $5^{\text {th }}$ Conference, American Institute of Physics, Volume 653, pp. 498-507 (2003).

5. C. A. Wang, C. J. Vineis, H. K. Choi, M. K. Connors, R. K. Huang, L. R. Danielson, G. Nichols, G. W. Charache, D. Donetsky, S. Anikeev and G. Belensky, "Lattice-matched GaInAsSb / AlGaAsSb / GaSb Materials for Thermophotovoltaic Devices", Proceedings of Thermophotovoltaic Generation of Electricity: $5^{\text {th }}$ Conference, American Institute of Physics, Volume 653, pp. 324-334 (2003).

6. G. W. Charache, P. F. Baldasaro, L. R. Danielson, D. M. DePoy, M. J. Freeman, C. A. Wang, H. K. Choi, D. Z. Garbuzov, R. U. Martinelli, V. Khalfin, S. Saroop, J. M. Borrego, and R. J. Gutmann, "InGaAsSb Thermophotovoltaic Diode: Physics Evaluation", Journal of Applied Physics, Volume 85, Number 4, pp. 2247 - 2252 (1999).

7. M. E. Flatté, C. H. Grein, H. Ehrenreich, R. H. Miles, and H. Cruz, "Theoretical Performance Limits of 2.1-4.1 $\mu \mathrm{m}$ InAs/InGaSb, HgCdTe, and InGaAsSb lasers", Journal of Applied Physics, Volume 78, Number 7, pp. 4552-4559 (1995).

8. C. H. Grein, P. M. Young, M. E. Flatté and H. Ehrenreich, "Long Wavelength InAs/InGaSb Infrared Detectors: Optimization of Carrier Lifetimes" Journal of Applied Physics, Volume 78, Number 12, pp. 7143-7152 (1995).

9. S. Saroop, J. M. Borrego, R. J. Gutmann, G. W. Charache, and C. A. Wang, "Recombination Processes in Doubly-Capped Antimonide-Based Quaternary Thin Films", Journal of Applied Physics, Volume 86, Number 3, pp. 1527 - 1534 (August 1999).

10. R. K. Ahrenkiel, "Contactless measurement of recombination lifetime in photovoltaic materials", 26th IEEE Photovoltaic Specialists Conference, Anaheim, CA (1997).

11. D. A. Clugston and P. A. Basore, "PC 1D Version 5: 32-Bit Solar Cell Modeling on Personal Computers", 26th IEEE Photovoltaic Specialists Conference, Anaheim, CA (1997). 